\title{
Movimentos de resistência no Sistema Único de Saúde (SUS):
} a participação rizomática*

\author{
Bruna Ceruti Quintanilha1 \\ Francis Sodré2 \\ Maristela Dalbello-Araujo ${ }^{3}$
}

QUINTANILHA, B.C.; SODRÉ, F.; DALBELLO-ARAUJO, M. Resistance movements in the Brazilian National Health System (SUS): rhizomatic participation. Interface (Botucatu), v.17, n.46, p.561-73, jul./set. 2013.

Social participation in the Brazilian National Health System (SUS) ensures that users have an important influence on its construction. However, we postulated that various ways of manifesting this participation exist, going beyond those already instituted. We took the view that these are resistance movements, called rhizomatic participation. With the aim of mapping their occurrence in the daily routine of health centers, we created strategies and instruments within a qualitative research approach inspired by a cartographic stance and implication analysis. The movements perceived were grouped into three types of analysis providers: those that said things, those that said bad things and those that said nothing. We took into consideration the conditions that gave rise to occurrences and the effects that these conditions produced. We suggest that rhizomatic participation movements should be understood as health service analysis points, because making them explicit makes it possible to rethink the practices instituted within SUS.

Keywords: Social participation. Brazilian National Health System. Health Centers.
A participação social no SUS assegura a importância da interferência do usuário para sua construção. Entretanto, postulamos que existem várias formas de manifestação da participação, para além das já instituídas, que afirmamos serem movimentos de resistência, denominados de participação rizomática. Com o intuito de mapear sua ocorrência no cotidiano de unidades de saúde, criamos estratégias e instrumentos inscritos na abordagem qualitativa em pesquisa, inspirados na postura cartográfica e na análise da implicação. Os movimentos percebidos foram agrupados em três tipos de analisadores: os ditos, os mal ditos e os não ditos. Consideramos as condições que propiciaram a ocorrência e os efeitos produzidos por eles. Sugerimos que os movimentos de participação rizomática devem ser entendidos como pontos de análise dos serviços de saúde, pois sua explicitação possibilita repensar as práticas instituídas no SUS.

Palavras-chave: Participação Social. Sistema Único de Saúde. Centros de Saúde.
*Elaborado com base em Quintanilha (2012); pesquisa realizada com bolsa da Coordenação de Aperfeiçoamento de Pessoal de nível Superior (Capes). ${ }^{1}$ Centro de Referência da Assistência Social de Vitória. R. Santa Rita de Cássia, n.160, Bairros de Lourdes. Vitória, ES, Brasil. 29042-753. quintanilhabc@gmail.com 2,3 Programa de Pós-Graduação em Saúde Coletiva, Universidade Federal do Espírito Santo. 


\section{Introdução}

A participação social é considerada uma das maiores conquistas do Sistema Único de Saúde (SUS), uma vez que inclui a população como gestora deste sistema. Essa conquista é fruto de movimentos sociais iniciados na década de 1970, que culminaram na constituição do sistema de saúde brasileiro, em 1990 (Luz, 2007; Gerschman, 2004; Labra, Figueiredo, 2002; Dagnino, 2002).

Moreira (2008, p.15) ressalta que institucionalizar os Conselhos e Conferências de Saúde no Brasil, "definindo-os como as instâncias mandatórias responsáveis pela promoção da participação da sociedade na gestão do SUS, foi uma ousadia democratizante que apontava para uma proposta de reforma política". Com a regulamentação da lei 8.142/90, a interferência dos usuários no sistema passa a ser legitimada. Esta lei estabelece as instâncias colegiadas dos Conselhos e Conferências de Saúde, em cada esfera de governo, como mecanismos para efetivação da participação, instâncias que são compostas por gestores, profissionais da saúde e usuários. Estes detêm representação paritária em relação aos demais segmentos. Assim, do total de conselheiros que os constituem, $25 \%$ são representantes de gestores, 25\% de profissionais e 50\% de usuários (Brasil, 1990).

Entretanto, diversos autores têm apontado que a participação social não se restringe às instâncias instituídas. Nesse sentido, Longhi e Canton (2011) afirmam que se faz necessário encontrar outras vias de mobilização para que os direitos dos usuários sejam assegurados. Costa e Lionço (2006) reforçam essa premissa ao proporem o fortalecimento da vocalização de grupos sociais. Já Soratto, Witt e Faria (2010), Guizardi, (2009, 2008) e Brasil (2009) discutem que o processo de participação deve estar vinculado também a outros espaços, os quais devem ser mais flexíveis e porosos do que as instâncias de participação já existentes (Brasil, 2006). De acordo com Guizardi (2009), a participação do usuário tem sido cerceada pelos mecanismos instituídos, tornando-os menos eficazes no propósito de serem locais de vocalização política da sociedade civil. O documento ParticipaSus (Brasil, 2005) ressalta que a gestão participativa se encontra presente no cotidiano dos serviços de saúde. Dalbello-Araujo (2005) observa que a população participa da construção do SUS, mesmo quando esta não acontece nos moldes institucionais previstos pelas diretrizes. Segundo a autora, a população "participa porque produz tensão, gera conflito, exige mudança de posturas" (Dalbello-Araujo, 2005, p.160).

Em recentes pesquisas realizadas sobre os processos de trabalho nas Unidades de Saúde, Quintanilha e Dalbello-Araujo (2009), Iglesias (2009) e Faria (2010) puderam mapear os jogos de força que perpassam a relação entre usuário e profissionais, no cotidiano dos serviços, e concluíram que os usuários se utilizam de diversos meios para anunciar o que pensam e querem. De acordo com Iglesias (2009, p.122), a população inventa formas para impedir que a controlem e assinala: "o usuário se afirma como gestor e inventor de sua própria vida, baseado em seus interesses e valores. Isso [...] [resgata] a importância de tomar os sujeitos como imprescindíveis no processo de produção de saúde". Segundo Quintanilha e Dalbello-Araujo (2009), os usuários criam brechas para se expressarem, mesmo quando não são convidados a dizer o que sentem ou pensam. Faria (2010) constatou que a participação social em Unidades de Saúde, por vezes, se manifesta na forma de gritos e confusões.

Em nosso entendimento, essas manifestações são formas de resistência, movimentos que vão de encontro à ordem estabelecida (Foucault, 2006; Oliveira, 2001). A essas formas de participação denominamos participação rizomática (Quintanilha, 2012). Neste artigo, explicitaremos sua conceituação e a cartografia de sua configuração no cotidiano de seis Unidades de Saúde, componentes da região de Maruípe, no município de Vitória/ES.

\section{Os movimentos de resistência e a participação rizomática}

Os usuários participam a seu modo do cotidiano dos serviços de saúde. Assim sendo, podemos afirmar que a participação social também se efetiva em espaços diferentes dos já institucionalizados e assegurados por lei, tais como os Conselhos e Conferências de Saúde. É inegável que a população provoca interferências nos serviços de saúde, e movimentos se materializam e ganham corpo nas mais diversas formas, ainda que, muitas vezes, sejam abafados ou calados. Fica evidente que as formas encontradas pela população para participar e interferir nos serviços de saúde podem ser tomadas como 
movimentos de resistência, como descritos por Foucault (2006). Para ele, as resistências são distribuídas de modo irregular:

Os focos de resistências disseminam-se com mais ou menos densidade no tempo e no espaço, às vezes provocando o levante de grupos ou indivíduos de maneira definitiva, inflamando certos pontos do corpo, certos momentos da vida, certos tipos de comportamento. [...] É mais comum, entretanto, serem pontos de resistência móveis e transitórios, que introduzem na sociedade clivagens que se deslocam rompem unidades e suscitam reagrupamentos, percorrem os próprios indivíduos, recortando-os e os remodelando, trançando neles, em seus corpos e almas, regiões irredutíveis. (Foucault, 2006, p.106)

Os movimentos de resistência extravasam o significado de se opor a algo ou a alguém, eles envolvem a criação e a mudança no que está estabelecido. Como afirma Oliveira (2001, p.56), as resistências são "uma criação sempre social de outras possibilidades de vida". Muitas vezes, são ações empreendidas sem uma intenção preestabelecida, isto é, não há um planejamento prévio do agir. No entanto, Romagnoli et al. (2009) afirmam que, se existe resistência, é porque não há total captura das forças inventivas da vida. Assim, se há produção de novas formas de vida, é porque existem movimentos de resistência.

As resistências quebram ou questionam uma forma hegemônica e preestabelecida de funcionamento das instituições. Neste contexto, estas não correspondem às estruturas físicas ou prédios. De acordo com Lourau (2004a, p.71), instituições são normas, que "incluem também a maneira como os indivíduos concordam, ou não, em participar dessas mesmas normas". O autor ressalta que as relações sociais fazem parte do conceito de instituição. Com base nessa análise, entendemos que as instituições devem ser tomadas como relações consideradas comuns ao modo de funcionamento do serviço de saúde, da família, da escola, da fábrica, da loja, do presídio.

Os incômodos são produzidos a partir das relações que os sujeitos estabelecem entre si, provocando movimentos de resistência. Todo encontro é perpassado por jogos de forças que produzem tensão, modificando a conformação das forças que perpassam e compõem os corpos, pois, não é possível afirmar que este ou aquele encontro provocou o incômodo. Porém, se há produção deste é porque há desejo de mudança. Podemos afirmar, então, que as resistências são movimentos de participação social, exatamente porque se constituem como fruto de afetações que houve na trajetória das pessoas e emergem no sentido da afirmação de um desejo de que algo seja diferente daquilo que é dado.

No contexto dos serviços de saúde, os movimentos de resistência expressam os desejos dos usuários em relação ao que está estabelecido, sendo as resistências uma forma de o usuário participar de sua gestão. Sem dúvida, um modo menos articulado de se expressar sobre o serviço do que aqueles elaborados nas Conferências de Saúde, mas, não menos eficiente, porque pode ter tantas repercussões no modo de funcionamento do serviço quanto as deliberações dos espaços instituídos.

Estar atento ao cotidiano, à lógica solta das relações que se dão dentro das instituições significa pensar a política pela ótica da experimentação - política baseada no experimento. A política de participação não é apenas a mobilização da necessidade de estar contra ou a favor (Lazzarato, 2006), há uma necessidade de engajamento, da ação em prol da igualdade subordinada ao acontecimento. Pensar os movimentos de resistência e participação para além do âmbito das conferências ou das ações instituídas representa pensar uma política do devir, uma política concebida como experimentação, o que nos coloca cautelosos para compreendermos que consideramos, como político, tudo aquilo que é relacional, potente por ser instituinte.

Às formas de participação que se caracterizam como movimentos de resistência - que criam, inventam, produzem novos modos de existência, novas normas para a vida -, denominamos participação rizomática. Atribuímos-Ihes o adjetivo rizomática por serem amorfas, ou melhor, não possuírem uma forma exata para emergirem. Deleuze e Guatarri (1996, p.22) afirmam que "[u]ma das características mais importantes do rizoma talvez seja a de ter sempre múltiplas entradas". Ou seja, ele não tem começo nem fim determinado, pode ser visto através de diferentes ângulos e está sempre em 
transformação. De acordo com Deleuze e Guatarri (1996), o rizoma é um sistema não centrado. Equiparar esse modo de participação ao rizoma é atribuir-Ihe o adjetivo de ruptura, de descontinuidades difíceis de mapear. É, assim, oposto às arvores, que têm estrutura e raízes, cujo tronco equivale ao centro, e os galhos, às suas repartições.

A participação rizomática se caracteriza, então, por não ter uma forma preestabelecida de existência ou ocorrência. Esses movimentos são lutas empreendidas no cotidiano do serviço que emergem das relações entre aqueles que o compõem. Tanto trabalhadores como usuários resistem. Contudo, em nossa pesquisa, privilegiamos o mapeamento dos movimentos que emergem das ações de usuários, para reverberar uma forma que tem sido pouco valorizada e contrapor às ideias de que os usuários são agentes que não participam.

Afirmar que a participação do usuário é pequena (Trad, Esperidião, 2009; Escorel, 2008) orienta a solução de que é preciso ensiná-lo sobre a importância de participar dos conselhos ou de que é necessário capacitá-los para agirem como tal. Afirmar que há pouca participação e pouca assiduidade nos espaços consagrados como mecanismos instituídos de participação (conselhos, conferências locais) sugere que o conceito de representação está em crise. Não obstante, é preciso estar atento ao sentido das ausências, que também podem significar um protesto silencioso de resistência contra o sistema representacional que está repleto de descrédito.

Essa maneira de conceber os usuários pode estar relacionada com o fato de eles serem vistos apenas como demandantes no serviço de saúde. Trad e Esperidião (2009, p.567) sugerem que "compartilhar com os usuários os problemas enfrentados pelas equipes no dia-a-dia [sic] do seu trabalho e pelo qual são responsáveis contribuiria para tirar o usuário de uma posição de 'demandante': alguém que espera pacientemente (ou não) que suas necessidades de saúde sejam atendidas".

Admitir o usuário como demandante reforça a ideia de que, para haver mudanças, é preciso dar voz à população. Entretanto, considerar que os movimentos de resistência são formas de participação social - denominadas participação rizomática -, significa afirmar que a população tem voz, que ela expõe suas necessidades e desejos no cotidiano dos serviços; ocorre que, muitas vezes, essa forma de participação não chega a ser ouvida. Como afirma Foucault, a população não precisa dos especialistas para saber o que fazer, "elas sabem perfeitamente, claramente, muito melhor do que eles, e o dizem muito bem. Mas, existe um sistema de poder que barra, proíbe, invalida esse discurso e esse saber" (Foucault, 1979, p.71).

No dia a dia das Unidades de Saúde, o usuário, com frequência, tem seu saber desconsiderado e suas falas ignoradas. Essa postura acaba por cercear os movimentos de interferência no serviço por parte dos usuários. Entender a política como exercício cotidiano impõe reconhecer, nesses homens e mulheres, sujeitos capazes de diálogo e decisão. Para tanto, deve-se estimular a proliferação de trocas e reflexões entre profissionais, e destes com a comunidade, e, desse modo, construir práticas de saúde a partir da solidariedade, do respeito e do mútuo reconhecimento, pois, dessa forma, se criam condições de estímulo para a invenção de saídas coletivas para os problemas (Dabello-Araújo, 2005).

Diante do exposto, propusemo-nos a mapear os movimentos de participação rizomática que emergem das ações dos usuários no cotidiano de seis Unidades de Saúde de uma região do Município de Vitória, ES.

\section{Metodologia}

Para mapear as manifestações da participação rizomática no cotidiano de Unidades de Saúde, foi preciso acompanhar processos e criar instrumentos que permitissem dar visibilidade a elas. A pesquisa se baseou na abordagem qualitativa, porque esta permite investigar o mundo social por meio das vivências, das experiências e da cotidianidade (Romagnoli, 2009), proporcionando aproximação e intimidade entre o pesquisador e o que está sendo pesquisado. 
${ }^{4} \mathrm{O}$ projeto $\mathrm{da}$ pesquisa foi aprovado pelo Comitê de Ética da Universidade Federal do Espírito Santo e pela Secretaria Municipal de Saúde do município de Vitória, ES.
Para a realização do campo da pesquisa ${ }^{4}$, elegemos seis Unidades que fazem parte de uma das Regiõ̃es de Saúde do Município de Vitória, Espírito Santo. Vale ressaltar que, em todos os serviços da rede de saúde, é possível mapear a participação rizomática, já que ela não possui um local específico para acontecer. Entretanto, elegemos as Unidades por entendermos que elas propiciam uma relação mais próxima com o usuário, posto que eles frequentam assiduamente esses serviços.

Em dezembro de 2010, apresentamos a proposta da pesquisa aos coordenadores das Unidades, e, após conhecimento e consentimento, passamos a frequentá-las diariamente, até junho de 2011. Apresentar a pesquisa aos coordenadores foi importante para que pudessem ser sanadas as dúvidas relativas à metodologia, e pudéssemos assegurar-Ihes a não-necessidade de alteração da rotina do serviço. Em relação aos demais profissionais, entendemos não ser necessária a explicitação detalhada dos propósitos da pesquisa, pois o conhecimento sobre a mesma poderia alterar o modo das relações com os usuários. Neste ínterim, participamos da Conferência de Saúde do Município de Vitória. Tal decisão se deu por reconhecermos que a presença nesse local poderia contribuir para verificar como se dá a tessitura da relação entre usuário-profissional em espaços instituídos de participação.

Para investigarmos os movimentos cotidianos de participação, mais especificamente, para mapearmos quais formas assumiram os movimentos de participação rizomática, colocamo-nos na postura de cartógrafos. Trata-se de uma postura metodológica e política relativa à maneira como estabelecemos nossas relações, que se coadunam com o modo como entendemos sua produção histórica, a partir dos jogos de poder. De acordo com Romagnoli (2009, p.169), a "cartografia se apresenta como valiosa ferramenta de investigação, exatamente para abarcar a complexidade, zona de indeterminação que a acompanha, colocando problemas, investigando o coletivo de forças em cada situação". Kastrup $(2009,2007)$ complementa, afirmando que a cartografia sempre investiga um processo de produção, que é um método ad hoc, ou seja, que se constrói caso a caso.

A postura cartográfica parte de uma reversão metodológica que desafia o pesquisador a transformar metá-hódos em hódos-metá. Por método (metá-hódos) se entende que a pesquisa possui um caminho predeterminado para alcançar as metas ou objetivos (Passos, Kastrup, Escóssia, 2009). De acordo com Ferigato e Carvalho (2011, p.668), com essa reversão, o que se propõe é o "primado do caminho, e não da meta, [isso] faz com que a pesquisa seja, antes de tudo, uma experimentação, um processo em aberto em que operam séries de dobras e desdobras, de inesgotáveis problemas e descobertas."

A postura cartográfica aposta na experimentação como atitude, isto é, afirma que a pesquisa é tão normativa quanto a vida, logo, está em constante transformação e ressignificação. O pesquisador se lança a experimentar os encontros proporcionados pela pesquisa, com a clareza de que não sabe, ao certo, o que irá encontrar, nem o que resultará desses encontros. A escolha pelo método cartográfico fez-se, nesta pesquisa, por reconhecermos que a participação rizomática surge dos encontros com formas imprevisíveis. Assim, era preciso que o sentir do pesquisador fosse considerado para se tomar conhecimento de como eram os movimentos que emergiam dos encontros cotidianos nas Unidades de Saúde. Isso porque, seria desde como o pesquisador evidenciasse o que emerge dos encontros que poderíamos desenhar quais formas a participação rizomática pode ter.

A pesquisa se constituiu em uma caminhada na qual utilizamos várias ferramentas, dentre elas, o diário de ocorrências. As ocorrências cotidianas se fazem no acontecimento, no acaso do encontro, assim como a participação rizomática. 
diário consiste no registro de todas as informações, sensações e percepções obtidas no campo de pesquisa. De acordo com Minayo (2007), é interessante o investigador registrar a maior diversidade possível de pensamento e, também, de emoções.

De acordo com Hoffman (2009, p.57), o resultado do percurso feito pelo cartógrafo "é uma experiência expressiva dos encontros que foram se fazendo e das relações singulares que se construíram durante o processo de pesquisar". Estabelecemos a relação com o campo da pesquisa, levando em conta que somos afetados por ele e, também, o afetamos. Por isso, compreendemos que o conceitoferramenta de análise da implicação, advindo da Análise Institucional, nos permite depreender os jogos de forças que produzem os movimentos de participação rizomática.

A análise da implicação põe "em evidência o jogo de interesses e de poder encontrados no campo de investigação" (Paulon, 2005, p.23); dessa forma, é importante analisar a si mesmo e aos outros a todo momento (Lourau, 1993). "Estar implicado (realizar ou aceitar a análise de minhas próprias implicações) é [...] admitir que sou objetivado por aquilo que pretendo objetivar: fenômenos, acontecimentos, grupos, idéias, etc." (Lourau, 2004b, p.147-8). Lourau (2004a) afirma, também, que a análise visa a evidenciar as relações estabelecidas entre elementos aparentemente independentes, e o processo visa a decompor os movimentos captados, e não interpretá-los. Isto é, "[n]ão se trata de construir um discurso explicativo, mas de trazer à luz os elementos que compõem o conjunto" (Lourau, 2004a, p.70). Esses elementos revelados recebem o nome de analisadores.

Com base nessas reflexões, tomamos, como analisadores, os movimentos que registramos no diário de ocorrências. Eles se compuseram pelos questionamentos oriundos dos encontros e afetos produzidos durante o campo da pesquisa.

O registro dos incômodos produziu três pontos de análise: os ditos, os mal ditos e os não ditos. $O$ primeiro deles corresponde aos momentos em que vimos a participação rizomática ganhar forma. São movimentos em que os usuários criaram modos de se relacionarem com o serviço nos quais questionavam as relações estabelecidas e os protocolos impostos, ou reafirmavam formas de funcionamento que os agradavam. O encontro com esses movimentos explicitou que as relações construídas nos serviços são permeadas de afeto e de pontos de tensão que são impossíveis de serem previstos e enclausurados em normas e regras. Notamos, também, como é difícil, para o profissional, lidar com o imprevisível.

O segundo ponto de análise partiu dos movimentos que se manifestavam como que coartados, momentos que minavam sem constituir um acontecimento. Isso foi percebido quando os usuários se comunicavam entre si, criticando o serviço, ou quando ameaçavam chamar a mídia para resolver os problemas, sem que esse ímpeto se atualizasse em ação. Esses movimentos foram denominados analisadores mal ditos.

O terceiro analisador são os chamados de não ditos. Eles surgiram do incômodo produzido no cartógrafo, a começar pela não-ocorrência da participação rizomática. Assim, havia dias em que registrávamos que "nada" aconteceu na Unidade.

Neste artigo, explicitamos o que entendemos de cada um deles, sua forma de manifestação, e realizamos uma análise sobre a potência de transformação neles impressa.

\section{Ditos}

O primeiro analisador que discutimos neste artigo são os ditos, que correspondem aos movimentos de participação rizomática cartografados nas Unidades de Saúde. São compostos por pontos de resistência, movimentos de criação que questionam ou afirmam formas de funcionamento instituídas e quebraram protocolos estabelecidos (Romagnoli et al., 2009; Foucault, 2006; Pelbart, 2003; Deleuze, 1992). Os ditos expressam o desejo do usuário de efetivar mudanças no sistema de saúde, seja na forma como as relações estão construídas ou em seu modo de funcionamento.

Durante os seis meses em que frequentamos assiduamente as Unidades, pudemos mapear inúmeras ocorrências desses movimentos, e constatamos que eles se apresentam de diferentes formas. Notamos que os usuários, por vezes, expressam diretamente, ao profissional, uma avaliação daquilo que gostam ou não no serviço. Em outras ocasiões, percebemos que eles procuram diferentes profissionais para 
resolver um mesmo problema, assim como presenciamos situações em que os usuários solucionaram problemas uns dos outros sem que houvesse a interferência de um profissional. Entretanto, também evidenciamos diversas ocasiões em que manifestaram o que pensam ou o que querem aos gritos. $E$, como que, numa última tentativa, vimos muitos usuários saírem porta afora, afirmando que iriam buscar outro serviço que lhes resolvesse os problemas.

Consideramos esses movimentos como sendo participação rizomática por serem inventivos, imprevisíveis e possuírem formas diversas. Eles questionam o serviço de forma incerta, pois não se sabe em que resultarão, uma vez que se produzem no encontro. É impossível prever seu surgimento, assim como a intensidade de seu reverberar dentro do serviço, visto que são construídos nas relações, e a reverberação dependerá das ressonâncias que conseguirem obter.

A imprevisibilidade e a potência questionadora dos movimentos de participação rizomática ficaram evidentes em uma das cenas que presenciamos, na qual uma usuária mobilizou todos que estavam na Unidade, ao dizer, aos gritos, que achava injusta a forma como as senhas de marcação de consultas foram distribuídas. Alegava que um usuário havia recebido mais de uma senha, o que fez com que outros ficassem sem. Essa manifestação teve grande impacto, e vários dos presentes se sentiram livres para opinar e acrescentar suas histórias. Uma delas completou que os agentes insistem para que ela vá à Unidade, mas de que adiantaria ir se não consegue ser atendida? Outra usuária pediu pela presença da coordenação e, para que isso não se realizasse, resolveu-se o impasse, oferecendo senhas aos que reclamaram. Mesmo depois de resolvido o conflito, alguns permaneceram discutindo o assunto entre profissionais e usuários do serviço. As opiniões se diversificavam, alguns concordaram com as reclamações dos usuários, outros afirmavam que havia prazer em tumultuar o serviço. Baseando-nos em nossos exemplos, afirmamos que os movimentos de participação rizomática, produzidos pelos usuários, manifestam-se no momento do encontro com alguma situação que os afeta de forma intensa, por isso, são processos micropolíticos e amorfos, logo, rizomáticos. São movimentos inconscientes e não possuem um planejamento prévio.

Lévy (2003, p.25) afirma que o inconsciente é composto de "agenciamentos coletivos de enunciação, os rizomas heterogêneos ao longo dos quais circulam nossos desejos e pelos quais se lançam e se relançam nossas existências". Quando um usuário produz um movimento de resistência, ele dá forma ao desejo e à vontade de outros usuários. Assim, o modo no qual a participação rizomática emerge resulta de diversos encontros anteriores à própria verbalização. Encontros ocorridos: no corredor da Unidade, no churrasco do fim de semana, na Igreja do domingo, na escola do filho, no ônibus que passa pelo bairro, no café em casa. Aquele que vocaliza não fala apenas por si, mas por todo um coletivo que compõe uma rede de encontros.

Entendendo que o coletivo é composto pelas experiências cotidianas e convoca o comum ${ }^{5}$ que envolve a relação com aquilo que faz parte do mundo, Escóssia (2003, p.186) assevera: "é incluindo o mundo e [é] nos compondo com ele que nos reinventamos e reinventamos o mundo." Digamos, então, que o usuário que fala é composto por muitos. No caso da participação rizomática, ao afirmarmos que um usuário dá forma ao desejo de outros, estamos falando do coletivo em nós que é construído nos encontros vividos com os vizinhos, os amigos, os parentes e as ocorrências do serviço.

A participação rizomática fala de um modo de expressão do desejo e deve ser entendida como uma forma de se repensarem relações. Com isso, afirmamos que ela se apresenta em qualquer espaço e possui diversas formas, podendo ser 
observada: no corredor da Unidade, na reunião de equipe, na consulta com o profissional de saúde, na igreja do bairro, na festa de aniversário da vizinha, no centro comunitário. A participação rizomática pressupõe liberdade, invenção e transformação. Tentar normalizá-la está no campo do impossível. Afinal, movimentos de resistência sempre existirão, já que se formam nas tensões entre forças. Essas tensões são produzidas nas relações que se constroem nos serviços: entre usuários, profissionais e as burocracias; enfim, entre tudo e todos que os compõem. A resistência mostra-se quando a tensão que se forma entre as forças produz incômodo.

Portanto, entendemos que os movimentos de participação rizomática devem ser tomados como analisadores das relações que estão estabelecidas no serviço de saúde, como atos que propiciem repensar a dinâmica do serviço e rever o que as relações entre atores e instrumentos ${ }^{6}$ estão produzindo. Entendemos que os ditos são formas de manifestação nas quais os usuários se posicionam em relação ao serviço. Seria fundamental que os profissionais os acolhessem, visto que eles poderiam oferecer inúmeras pistas de soluções aos problemas e gerar mudanças de posturas.

\section{Mal ditos}

O segundo analisador que discutimos neste artigo são os mal ditos. Se os ditos correspondem à participação rizomática, este analisador relaciona-se à sua imanência. Foram compostos por falas entre usuários nas quais manifestaram alguma opinião ou sugestão sobre o serviço, nenhum outro movimento foi empreendido no sentido de se efetivarem atos que culminassem em mudanças nas Unidades. Os analisadores mal ditos se caracterizaram como movimentos em que a ação não se evidenciava como uma tensão entre usuários e serviço. Vale ressaltar que, na ocorrência dos mal ditos, é possível observar que há um incômodo em relação ao que está estabelecido no serviço, porém, apesar de verbalizado, não se desdobra em ações que coloquem esse incômodo em questão.

Podemos nos questionar sobre o porquê de os usuários não transformarem seus incômodos em ação. Em algumas das ocorrências, tivemos a impressão de que havia um movimento de desresponsabilização por parte deles, como se estivessem esperando que alguém tomasse uma atitude, a partir das várias reclamações ali expressas. Todavia, o "verbalizador" não pôde ou não quis fazer nada. A partir disso, construímos três possíveis linhas de análise para esse não agir. Uma delas se refere ao fato de supormos que apenas movimentos sociais organizados - tais como sindicatos e associações - possuam ferramentas suficientes para provocarem mudanças naquilo que está imposto. Outra linha diz respeito ao papel que a mídia tem tomado na denúncia dos problemas e, com isso, consegue a resolução deles. Por último, em uma terceira linha de análise, inferimos se o sistema representacional estaria acarretando essa desresponsabilização, desde que se presuma haver sempre alguém que representa os interesses de seus pares, por isso, não se faz necessário agir. Ressaltamos que, neste artigo, iremos analisar apenas esta última questão, porquanto julgamos que as outras duas derivam, em certa medida, da terceira.

O sistema representacional adotado na maioria das instâncias de poder pressupõe que os representantes serão escolhidos por seus pares e, assim, o que possuir um quantitativo maior de votos será aquele com a força para defender melhor os interesses dos demais. Constitui uma premissa do sistema o fato de que alguns representem a vontade de todos ou da maioria. Em função disso, o usuário se coloca numa posição de passividade, já que naturaliza a ideia de que sempre haverá um outro que falará e lutará por ele. Asensi (2010) afirma que, na verdade, a forma de se relacionar com o sistema representacional faz parte da cultura cívica brasileira. Para ele, nossa cultura "é marcada muito mais pela passividade da sociedade civil do que por sua forte atuação na
${ }^{6}$ Por

instrumentos. entendemos: as regulamentações das Políticas e Programas ministeriais, o como funciona o fluxo de atendimento da Unidade, a forma como se faz a marcação de consultas, as fichas que precisam se preenchidas, e outros. 
efetivação, construção e garantia de direitos" (Asensi, 2010, p.23). Lattman-Weltman (2008) defende ser simbólica a representação, e que o representante não expõe, efetivamente, a vontade da maioria. Para Guizardi, (2009, p.14), o sistema representacional é tido como uma "prática política por excelência, força maior de expressão dos poderes 'do cidadão', cujo exercício político fica, desta forma, confinado num território próprio e distante de seu fazer cotidiano".

Vale afirmar que, geralmente, os usuários não são representados em sua totalidade nas instâncias instituídas pelo sistema representacional, e, como contraponto à ideia da representatividade, propomos pensar que o combate se dá no coletivo. A ideia extravasa a imagem de que cada segmento, grupo ou instituição luta por uma causa diferente, assim sendo, aposentados, mulheres, negros, gays, lésbicas, travestis, estudantes, professores, usuários, bancários possuem, como luta principal, o reconhecimento e a valorização da diferença. Valorizar e reconhecer a diferença é assumir que existem diversos modos de ser e que nenhum deles é melhor ou pior. As pessoas possuem desejos diferentes que as levam a ter prazer em diferentes modos de se relacionarem com as coisas e seres que compõem o mundo, pois, a luta do coletivo é a luta de todos, e não de um grupo específico.

Ademais, os mal ditos dizem respeito aos incômodos que os usuários sentem em relação ao serviço, portanto, há uma vontade de mudança que os perpassa. Desse modo, é possível afirmar que há um desejo em comum entre eles, contudo, esse desejo ainda não ganhou forma de maneira que possa ser manifestado e percebido. Sugerimos que profissionais e usuários ressignifiquem os mal ditos para que eles possam se atualizar de modo que consigam efetivar mudanças nas normas estabelecidas.

\section{Não ditos}

O terceiro analisador que discutimos são os não ditos, e correspondem a um contraponto dos ditos, porquanto são concebidos como os momentos em que sentimos que o nada aconteceu, ou melhor, constatamos a ausência da participação rizomática. Tal analisador se manifesta, para nós, a partir do incômodo sentido com a não-ocorrência dos movimentos. Com isso, colocamos em evidência nossa implicação no campo e na pesquisa, uma vez que a análise de implicação pressupõe que os jogos de força e poder emergem dos encontros ocorridos no campo da pesquisa (Paulon, 2005).

É importante ressaltar que, acompanhando o cotidiano das Unidades de Saúde, podem se ouvir ruídos dos ventiladores, dos carros na rua, o som da TV e das vozes de profissionais e usuários. Esse cotidiano é repleto de movimento. Todavia, eles nos pareceram sem vida. Podemos afirmar que algo era dito, porém sua expressão estava tamponada. Questionamos, pois, apesar de haver movimento, nos parecia que nada estava acontecendo.

Compreendemos que esses não ditos podem ter sido produzidos historicamente, a partir do silenciamento dos desejos dos usuários. Esse processo se relaciona com a construção da ideia de que, naquele espaço institucional, os profissionais são os únicos detentores de saber. Ao se colocarem nesse lugar, contribuem para o emudecimento dos usuários e para a não-expressão de seus desejos; portanto, para a permanência daquilo que está posto. A manutenção da relação saber-poder é feita por profissionais, pela academia, pelos veículos de comunicação. Com suas práticas e falas, todos eles reafirmam o status do saber acadêmico-científico na sociedade. Assim, se o profissional se coloca no lugar de professor, o usuário assume o papel daquele que nada sabe e precisa aprender.

Durante os meses em que acompanhamos o serviço das Unidades, ouvimos, diversas vezes, que o usuário não tem cultura, não tem conhecimento, não tem saber, não sabe o que quer. Discordando, a pesquisa de Trad e Esperidião (2009) afirma que são os profissionais de saúde os que têm dificuldade em valorizar o saber do usuário. Segundo os mesmos autores, os profissionais sabem da importância de se horizontalizarem as relações, recusando posturas hierárquicas, mas, ao mesmo tempo, assumem que seu saber é superior ao do usuário. Não há duvida de que o saber deste é diferente do saber técnicocientífico, entretanto, deve ser valorizado, uma vez que representa as suas vivências e diz do seu querer.

Nesse jogo de forças, evidencia-se que os profissionais estão impregnados por um saber que dita o certo e o errado, e desconsidera o que não está nos manuais acadêmicos. Dessa forma, no cotidiano de trabalho, recorre-se ao que foi aprendido nas instituições de ensino e que, geralmente, corresponde a técnicas de disciplinarização dos usuários. Estes, de tanto sentirem seu saber e experiência sendo 
ignorados, tornam-se mudos em todos os espaços em que o saber-poder do profissional se faz presente. Trata-se de uma estratégia de despotencialização, ou seja, retiramos deles o desejo de ação; o que produz mortificação das vontades.

Afirmamos que produção de saúde é expansão da vida. Nesse raciocínio, sua promoção passa por construir, com o usuário, outras formas de se relacionar com o mundo. Calar os usuários é desconsiderar os movimentos de resistências que eles engendram e reforçar a relação saber-poder que produz adoecimento.

\section{Considerações finais}

Neste artigo, enunciamos uma nova conceituação de participação social, que nomeamos de participação rizomática. Ela é composta por movimentos cotidianos que emergem na forma de resistências. Resistir é criar, inventar, produzir novos modos de existência, novas normas para a vida. Essa forma de participação reverbera a opinião dos usuários em relação ao serviço de saúde: dar visibilidade a ela é repensar o que está posto como certo ou natural.

Para que pudéssemos mapear movimentos de participação rizomática, colocamo-nos na postura de cartógrafos, por entendermos que esta escolha metodológica se coaduna com a postura política relativa ao modo como estabelecemos nossas relações e como estas se constituem historicamente. Para analisar aquilo que foi mapeado, utilizamos a análise de implicação, concepção construída pela Análise Institucional, da qual surgiram analisadores das relações de poder.

Durante nosso percurso nas Unidades de Saúde pesquisadas, percebemos quão diversos são os movimentos de participação rizomática que partem dos usuários, e, assim, afirmamos que os usuários, em muitos momentos, vocalizam seus desejos e demonstram o que querem e esperam dos serviços de saúde, apesar de crermos que tais movimentos não são valorizados pelos profissionais; na verdade, na maioria das vezes, foram desconsiderados. Originados na tensão de forças entre usuários e profissionais, emergiram movimentos que foram agrupados como pertencentes a três analisadores, que denominamos de ditos, mal ditos e não ditos. Estes se caracterizaram, respectivamente, pelos movimentos de participação rizomática, pela imanência destes e pela sua ausência.

Vale ressaltar que consideramos que a participação social acontece em diversos espaços nos serviços de saúde. Extravasa, pois, a ideia de que esta participação é restrita aos Conselhos e Conferências, e nos propusemos a mapeá-los como as formas de expressão dos desejos dos usuários em relação aos serviços de saúde. Logo, a participação ganha um contorno amórfico, ou melhor, passa a não ter modo nem local exato para ocorrer. Caracteriza-se, também, por questionar e incomodar o que está estabelecido como norma.

Concluímos que a participação rizomática é uma das formas que o incômodo ganha no corpo dos usuários. Contudo, ela costuma ser tomada de modo negativo nos serviços de saúde, pois é vista como um movimento que atrapalha e que causa mal-estar. Propomos ressignificar esses movimentos e, ao invés de associá-los a problemas, entendê-los como analisadores das relações instituídas nos serviços. Ou seja, os movimentos de participação rizomática devem ser tomados como atos dos usuários e apontam para questões em relação à Unidade que devem ser repensadas.

Ao considerarmos os movimentos de participação rizomática como analisadores, criamos a possibilidade de construir um serviço de saúde mais próximo das necessidades e desejos da população adscrita. Para tanto, por vezes, será preciso questionar as Políticas e os modelos de gestão impostos. Esclarecemos que questionar esses modelos, com base em de movimentos advindos da população, é reafirmar a participação social como diretriz norteadora do Sistema Único de Saúde.

\section{Colaboradores}

Os autores trabalharam juntos em todas as etapas de produção do manuscrito. 


\section{Referências}

ASENSI, F.D. Direito e usuários e saúde: três representações sobre a relação entre a forma e a alma. In: PINHEIRO, R.; LOPES, T.C. (Orgs.). Ética, técnica e formação: as razões do cuidado como direito à saúde. Rio de Janeiro: Cepesc, IMS/UERJ, Abrasco, 2010. p.15-32.

BRASIL. Ministério da Saúde. Secretaria de Atenção à Saúde. Política Nacional de Humanização da Atenção e Gestão do SUS. Gestão participativa e cogestão. Brasília: Ministério da Saúde, 2009.

. Ministério da Saúde. Secretaria de Gestão Estratégica e Participativa. Departamento de Apoio à Gestão Participativa. Participação Social em Saúde. Brasília: Ministério da Saúde, 2006.

Ministério da Saúde. Secretaria de Gestão Participativa. Política Nacional de Gestão Participativa para o SUS: PARTICIPASUS. Brasília: Ministério da Saúde, 2005.

. Lei 8142, de 28 de dezembro de 1990. Dispõe sobre a participação da comunidade na gestão do SUS e sobre as transferências intergovernamentais de recursos financeiros na área de saúde e dá outras providências. Diário Oficial da União Brasília, DF, 31 dez. 1990. Disponível em: <http://www.planalto.gov.br/ccivil_03/LEIS/ L8142.htm>. Acesso em: 15 maio 2010.

COSTA, A.M.; LIONÇO, T. Democracia e gestão participativa: uma estratégia para a equidade em saúde?. Saude Soc., v.15, n.2, p.47-55, 2006.

DAGNINO, E. Sociedade civil e espaços públicos no Brasil. São Paulo: Paz e Terra, 2002

DAlbello-ARAujo, M. O cotidiano de uma equipe do Programa de Saúde da Família: um olhar genealógico sobre o controle social. 2005. Tese (Doutorado) Programa de Pós-Graduação em Psicologia, Universidade Federal do Espírito Santo, Vitória. 2005.

DELEUZE, G. A vida como obra de arte. In: Conversações. Rio de Janeiro: Editora 34, 1992. p.118-26.

DELEUZE, G.; GUATTARI, F. Introdução: Rizoma. In: Mil Platôs. São Paulo: Ed. 34, 1996. v.1, p.11-37.

ESCOREL, S. Conselhos de saúde: entre a inovação e a reprodução da cultura política. Divulg. Saude Debate, n.43, p.23-8, 2008.

ESCÓSSIA, L. Por uma ética da metaestabilidade na relação homem-técnica. In: PELBART, P.P.; COSTA, R. (Orgs.). Cadernos de subjetividade: o reencantamento do concreto. São Paulo: Hucitec, 2003. v.1, n.1, p.177-86.

FARIA, H.X. No fio da navalha: o processo de trabalho de uma unidade de saúde da família de Vila Velha-ES. 2010. Dissertação (Mestrado) - Programa de Pós-Graduação em Psicologia Institucional, Universidade Federal do Espírito Santo, Vitória. 2010.

FERIGATO, S.H.; CARVALHO, S.R. Pesquisa qualitativa, cartografia e saúde: conexões. Interface (Botucatu), v.14, n.38, p.663-75, 2011.

FOUCAULT, M. História da sexualidade: a vontade de saber. 17.ed. São Paulo: Graal, 2006. Graal, 1979

Microfísica do poder. Org. e trad. Roberto Machado. Rio de Janeiro: Edições

GERSCHMAN, S. Conselhos Municipais de Saúde: atuação e representação das comunidades populares. Cad. Saude Publica, v.20, n.6, p.1670- 81, 2004.

GUIZARDI, F.L. Do controle social à gestão participativa: interrogações sobre a participação política no SUS. Trab. Educ. Saude, v.7, n.1, p.9-34, 2009. 
GUIZARDI, F.L. Do controle social à gestão participativa: perspectivas (pós-soberanas) da participação política no SUS. 2008. Tese (Doutorado) - Instituto de Medicina Social, Universidade do Estado do Rio de Janeiro, Rio de Janeiro. 2008.

HOFFMANN, C. Acolhimento na atenção básica: navegações e mergulhos nos discursos e práticas produzidos no cotidiano de uma unidade de saúde da família. 2009. Dissertação (Mestrado) - Programa de Pós-Graduação em Psicologia Institucional, Universidade Federal do Espírito Santo, Vitória. 2009.

IGLESIAS, A. Em nome da promoção à Saúde: análise das ações em macrorregião do município de Vitória-ES. 2009. Dissertação (Mestrado) - Programa de Pós-Graduação em Saúde Coletiva, Universidade Federal do Espírito Santo, Vitória. 2009.

KASTRUP, V. O funcionamento da atenção no trabalho do cartógrafo. In: PASSOS, E.; KASTRUP, V.; ESCÓSSIA, L. (Orgs.). Pistas do método da cartografia: pesquisaintervenção e produção de subjetividade. Porto Alegre: Sulinas, 2009. p.32-51.

. O funcionamento da atenção no trabalho do cartógrafo. Psicol. Soc., v.19, n.1, p.15-22, 2007.

LABRA, M.E.; FIGUEIREDO, J. Associativismo, participação e cultura cívica. O potencial dos conselhos de saúde. Cienc. Saude Colet., v.7, n.3, p.537-47, 2002.

LATTMAN-WELTMAN, F. Democracia, representação, participação: a aposta do pluralismo institucional. Divulg. Saúde Debate, n.43, p.29-36, 2008.

LAZZARATO, M. As revoluções do capitalismo. Rio de Janeiro: Civilização Brasileira, 2006.

LEVY, P. Plissê fractal. In: PELBART, P. P.; COSTA, R. (Orgs.). Cadernos de subjetividade: o reencantamento do concreto. São Paulo: Hucitec, 2003. v.1, n.1. p.23-8.

LONGHI, J.C.; CANTON, G.A.M. Reflexões sobre cidadania e os entraves para a participação popular no SUS. Physis, v.21, n.1, p.15-30, 2011.

LOURAU, R. Objeto e método da análise institucional. In: ALTOÉ, S. (Org.). René Lourau: analista institucional em tempo integral. São Paulo: Hucitec, 2004a. p.66-86.

. Estado na análise institucional. In: ALTOÉ, S. (Org.). René Lourau: analista institucional em tempo integral. São Paulo: Hucitec, 2004b. p.140-56.

René Lourau na UERJ: análise institucional e prática de pesquisa. Rio de Janeira: UERJ, 1993.

LUZ, M.T. Ordem social, instituições e políticas de Saúde no Brasil: textos reunidos. Rio de Janeiro: Cepesc, IMS/Uerj, 2007.

MINAYO, M.C.S. Trabalho de campo: contexto de observação, interação e descoberta. In:___ (Org.). Pesquisa social: teoria, método e criatividade. 26.ed. Petrópolis: Vozes, 2007. p.61-77.

MOREIRA, M.R. Democracia participativa, democracia representativa e conselhos de saúde no contexto da reforma política. Divulg. Saude Debate, n.43, p.15-22, 2008

NEGRI, A.; HARDT, M. Multidão - guerra e democracia na era do Império. Rio de Janeiro: Record, 2005.

OLIVEIRA, S. P. Micropolitica do fracasso escolar: uma tentativa de aliança com o invisível. 2001. Dissertação (Mestrado) - Programa de Pós-Graduação em Educação, Universidade Federal do Espírito Santo, Centro Pedagógico, Vitória. 2001.

PASSOS, E.; KASTRUP, V.; ESCÓSSIA, L. Apresentação. In: (Orgs.). Pistas do método da cartografia: pesquisa-intervenção e produção de subjetividade. Porto Alegre: Sulinas, 2009. p.7-16. 
PAULON, S.M. A análise de implicação com ferramenta na pesquisa-intervenção. Psicol. Soc., v.17, n.3, p.18-25, 2005.

PELBART, P.P. Vida capital: ensaios de biopolítica. São Paulo: Iluminuras, 2003.

QUINTANILHA, B.C. Participação rizomática: um modo de participação social no sistema Único de Saúde. 2012. Dissertação (Mestrado) - Programa de Pós-Graduação em Saúde Coletiva, Universidade Federal do Espírito Santo, Vitória. 2012.

QUINTANILHA, B.C.; DALBELLO-ARAUJO, M. Práticas em promoção da Saúde em Unidade de Saúde do Município de Serra-ES. Relatório final de Pesquisa PIBIC/UFES, PRPPG. Vitória: Universidade Federal do Espírito Santo, 2009.

ROMAGNOLI, R.C. A cartografia e a relação pesquisa e vida. Psicol. Soc., v.21, n.2, p.166-73, 2009.

ROMAGNOLI, R.C. et al. Por uma clínica da resistência: experimentações desinstitucionalizantes em tempos de biopolítica. Interface (Botucatu), v.13, n.30, p.199-207, 2009.

SORATTO, J.; WITT, R.R.; FARIA, E.M. Participação popular e controle social em saúde: desafios da Estratégia Saúde da Família. Physis, v.20, n.4, p.1227-43, 2010.

TRAD, L.A.B.; ESPERIDIAO, M.A. Gestão participativa e corresponsabilidade em saúde: limites e possibilidades no âmbito da Estratégia de Saúde da Família. Interface (Botucatu), v.13, supl.1, p.557-70, 2009.

QUINTANILHA, B.C.; SODRÉ, F; DALBELLO-ARAUJO, M. Movimientos de resistencia en el Sistema Único de Salud Brasileño (SUS): participación rizomática. Interface (Botucatu), v.17, n.46, p.561-73, jul./set. 2013.

La participación social en el Sistema Único de Salud Brasileño (SUS) asegura la importancia de la interferencia del usuario para su construcción. Sin embargo, afirmamos que hay diversas formas de manifestación de la participación además de las ya instituidas que afirmamos son movimientos de resistencia, denominados de participación rizomática. Con el objetivo de mapear su existencia en el cotidiano de las unidades de salud, creamos estrategias e instrumentos inscritos en el abordaje cualitativo en investigación, inspirados en la postura cartográfica y en el análisis de la implicación. Los movimientos percibidos se agruparon en tres tipos de analizadores: los dichos, los mal dichos y los no dichos. Consideramos las condiciones que propiciaron la existencia y los defectos producidos por ellos. Sugerimos que los movimientos de participación rizomática deben entenderse como puntos de análisis de los servicios de salud, puesto que su explicación posibilita repensar las practicas instituidas en el SUS.

Palabras clave: Participación social. Sistema Único de Salud. Centros de Salud. 
